Brief Report

\title{
North-American Conference Highlights the Treatment of Trauma Utilizing Guided Imagery and
}

\section{Music}

\author{
Suzannah Scott-Moncrieff ${ }^{1}$, Bolette Daniels Beck ${ }^{2}$, Erin Montgomery ${ }^{3}$ \\ ${ }^{1}$ New York University, Steinhardt School's Department of Music and Performing Arts Professions, New York City, NY, USA \\ ${ }^{2}$ Aalborg University, Institute for Communication and Psychology, Aalborg, Denmark \\ ${ }^{3}$ Private practice, Halifax, Nova Scotia, Canada
}

\begin{abstract}
A report on the 2015 Association for Music and Imagery conference highlights papers that address clinical practice and research using Guided Imagery and Music for the treatment of trauma.
\end{abstract}
Keywords: GIM, The Bonny Method, Music and Imagery, Trauma, PTSD, Refugees

multilingual abstract $\mid$ mmd.iammonline.com

In July 2015, the Association for Music and Imagery met for their biennial North American conference in New Jersey. In light of the refugee crisis exploding across Europe, the prevalence of troops returning from war zones around the world with post traumatic stress disorder (PTSD), and the new awareness about the effects of adverse childhood experiences (ACE) [1], it is no surprise that a significant number of research and clinical papers at the conference were focused on treating the symptoms of trauma.

The Association for Music and Imagery is an organization of facilitators, trainers, students, and supporters of The Bonny Method of Guided Imagery and Music. Helen Bonny developed this music-centered method of consciousness exploration in 1970. In its original form, clients listen to specially programmed classical music in an altered state of consciousness, in order to explore the realms of their imagination and ultimately experience a health-enhancing peak experience. Since her first trainees learned and spread the method, there are now over five hundred graduated Fellows of the AMI, worldwide, and thousands of individuals who have completed an introductory course, or one or more

\footnotetext{
PRODUCTION NOTES: Address correspondence to:

Suzannah Scott-Moncrieff, MA, MT-BC, LCAT, FAMI 202 W 40th Street, Suite 403, New York, NY 10018, USA, E-Mail: musictherapist@gmail.com | COI statement: The authors declared that no financial support was given for the writing of this article. The authors have no conflict of interest to declare. Suzannah Scott-Moncrieff and Erin Montgomery are unpaid board members for the Association for Music and Imagery.
}

levels of training in the method.

Clinicians and trainers educated in The Bonny Method of Guided Imagery and Music, as well as Helen Bonny herself, have gone on to creatively explore and develop ways of adapting the original method, to work with groups and individuals with significant psychiatric diagnoses [2]. From here on, The Bonny Method will refer to Helen Bonny's precomposed classical music programs, listened to in a deeply relaxed and non-ordinary state of consciousness. Guided Imagery and Music (GIM) or Music and Imagery here refers to the creative expansions of the method, including using single pieces of music, non-classical genres of music, drawing or listening to music with eyes open, spontaneous programming of music, and other variants.

At this year's conference, Dr. Lisa Summer's Opening Keynote, Addressing Diversity [3], outlined a Continuum Model of Music and Imagery that she developed to meet the many and varied needs of individual clients. For clinicians working in the trauma field, her Continuum Model suggests a very effective approach to working with clients with trauma diagnoses, given that it allows a GIM clinician to sensitively vary elements outlined within the original Bonny Method (including type and length of music, or state of consciousness) depending on the immediate and specific needs of the traumatized client, who may be emotionally dysregulated or dissociative.

In their paper entitled Trauma Informed Guided Imagery and Music: A Phase-Oriented Approach [4], Scott-Moncrieff (USA) and Montgomery (Canada) looked specifically at the Continuum of Music and Imagery Model and proposed a parallel to Judith Herman's Phase-Oriented approach to trauma treatment [5]. They demonstrated how Summer's 
stages of resource-oriented, insight-oriented, and reconstructive music and imagery and GIM, align well with Herman's three stages of trauma treatment: Safety and Stabilization, Remembrance and Mourning, and Reconnection and Integration.

Scott-Moncrieff provided an overview of the benefits of guided music listening experiences for those with complex trauma symptoms, including the ability of music to act as a symbolic container for internal experiences; to regulate affect and expand the window of affect tolerance; to slow down a client's experience for better integration; to promote connection to the body; to introduce qualities of playfulness and creativity where rigidity and dissociation are present; and to evoke imagery and inspire imaginative solutions to problems.

Montgomery presented three case examples, the first demonstrating how music, including non-classical music and music chosen by the client, can be used to accomplish affect regulation for a client working at the necessary stage of Safety and Stabilization. She provided a clinical example of using more complex, classical music to expand the same client's window of affect tolerance, increasing the client's capacity to be present with more challenging somatic and emotional experiences at Judith Herman's second stage of Remembrance and Mourning.

The second case example described an individual who had experienced early relational trauma, as well as an abusive relationship as an adult. Montgomery explored the complex inner world of this client using Internal Family Systems (IFS) as a model for the process [6]. Montgomery's choice to play one piece of music, repeated several times, allowed the client to imaginatively spend time with a previously disavowed part of herself, feel increasingly familiar and safe with this part, and eventually integrate it into her sense of Self.

The final case vignette demonstrated work with a client who had experienced incestuous sexual abuse as a child, and exemplified the way music may evoke bodily movement and effect change on a somatic level. Using repeated classical music, and through the client's visual and kinesthetic imagery, the somatic tension that the client had been holding related to her complex trauma, began to unravel. The physical tension had previously hindered her from connecting with others on a deeply intimate level. Through the GIM experience, the client experienced a "rebuilding" of her body, in line with Herman's final stage of Reconnection and Integration.

Dr. Dirk H. Walter, MD, from Berlin, Germany, presented a paper entitled GIM and its Adaption in the Treatment of Combat-Related PTSD with Veterans [7], detailing his clinical work using spontaneous music-choice and repeated music (as opposed to Bonny Method precomposed music programs) to address core PTSD symptoms of intrusion, hyper-arousal and avoidance, disempowerment, and disconnection.
Walter's presentation provided an overview of the current research on the effects of combat trauma on the body and mind. Walter is especially interested in the neurofunctional perspective and how trauma synthesis seems to be based on cortico-subcortical integration via emotional processing (bottom-up) and forming narrative (top-down). Music provides access to both bottom-up and top-down processes: it accesses the limbic system and supports emotional processing while also supporting the formation of a coherent trauma narrative. This is because the human brain "does not treat language and music as strictly separate domains, but rather treats language as a special case of music." [8]

Walter showed a video example of his work with a female patient who was experiencing combat-related PTSD: the patient sat upright, with her eyes closed, remembering and telling the therapist a traumatic experience. Using spontaneously chosen and seamlessly linked recorded music, Walter skillfully guided a trauma processing experience utilizing elements of GIM, EMDR, and IRRT (Imagery Rescripting and Reprocessing Therapy).

The footage shown was a moving example of the profound impact of war-trauma on the human psyche, and the ability of music to act as a container and modulator for powerful internal experiences. Walter continuously checked in with the patient regarding her Subjective Unit of Distress (SUDS) rating, while intuitively choosing music that allowed her to stay with the tension and re-experience her trauma with a different outcome. Dr. Walter demonstrated how music selections not only contained the patient's distress, but further, how they led her to a resolution: restoring a sense of inner calm and social connection, and providing her with a renewed sense of empowerment.

From Denmark, Bolette Daniels Beck, PhD, MT, FAMI, reported on preliminary results from an ongoing mixed methods research project, that explores the function and effect of music and imagery in the treatment of refugees diagnosed with post traumatic stress disorder [9].

For Dr. Beck and her fellow researchers, the question of whether music and imagery can help to cope with trauma is an urgent and important one, as it has been documented that almost 35\% of all refugees suffer from PTSD [10]. Research shows that PTSD affects deep layers in the brain, and that trauma reactions inhibit cognitive functions and verbalisation [11]. The rationale for implementing music and imagery is that music, too, affects these deep layers in the brain and can be used to regulate arousal and painful emotional states, wake up the social engagement system, and re-establish reflection and mentalisation.

Only a few studies on refugees and music therapy have been published [12]. A pilot study of music listening at sleep time with adult refugees showed significant effect on sleep quality [13], and a case study with three refugees demonstrated how music listening provided a transition from 
talking about bodily symptoms and pain to being able to integrate and reflect on emotions and traumatic experiences [14]. Until this research, no studies have investigated the effect of music and imagery in relation to refugees.

The research questions for this on-going study were: 1) What is the feasibility of using music and imagery with traumatised refugees? 2) What is the effect on trauma symptoms, sleep quality, well-being and social functioning?; 3) What do the participants find helpful?; and 4) What is the role of the music in the therapy? The research team was also interested in the degree to which the participants could use Western music, and whether they could use music for regulation of arousal and/or transformation of traumatic experiences.

The study took place in the research department of Psychiatry in Region Zealand, Denmark, from September 2014 and is due to be completed in December 2015. The therapies and data collection were carried out in a clinic for traumatised refugees by three part-time GIM Fellows/music therapists; one of them, project leader Torben Moe. The participants were adult refugees, who were referred from their GP, and diagnosed with posttraumatic stress disorder (PTSD). Participants were evaluated to have a high level of mentalisation during the visitation procedure in the clinic, and they all signed informed consent.

Included in the study were 10 men and 6 women with a mean age of 40 years (20-60 years), and they all came from Middle Eastern countries (Afghanistan, Iraq, and Syria). The participants received 16 weekly one-hour long sessions. In the visitation interview they each received a CD with 6 pieces of music (short pieces from the classical or meditative genres, with minimal tension or musical development), and they were instructed to choose the piece they liked the best, for listening to in the first sessions.

In the initial sessions the treatment focused on stabilisation and arousal regulation, finding inner secure places, breathing, and sensing the body to music. In some cases these goals remained the focus for the entire course of therapy. For some participants, a second phase focused on the ability to contain both positive and negative emotions, and pendulate between the two. And for some participants, the therapy progressed to the working-through of traumatic episodes or material. In order to avoid re-traumatization, the participants sat in an upright position, and could choose whether they would close their eyes during the musiclistening portion.

For the evaluation, a mixed methods design was created including a pre-post analysis of effect, with questionnaires and several qualitative analyses. The sessions were videotaped if the participants agreed. After all sessions, the participants were asked to rate the helpfulness of the session and describe the most helpful elements. After the termination of therapy, the participants were invited to do an interview.
The questionnaire data will be graphically screened and, within groups, significance tests and effect size calculations will be carried out. The initial analyses of participant evaluations of sessions indicate that the participants find the treatment very helpful, as the mean scores are in the high end. All the interviews have been transcribed, and five categories for the thematic analysis have been identified: a health dimension (improved health), an initiative dimension (more agency), a trauma treatment dimension, a music and imagery dimension (opinions on the use of the method) and a relational dimension (trust, relationships to therapist and important others). From the many hours of video recordings, the researchers have chosen to focus on the sections with music using purposive sampling: two short clips for each of the ten participants will all be analysed by four persons using a phenomenological analysis, with the aim of formulating meaning essences regarding the use of music with traumatized refugees.

Thus far, Beck and her fellow researchers have observed that all participants were able to listen to music in almost all the sessions; around 25\% primarily preferred music from their own culture; and most of the participants began to use or develop their use of music at home as a self-help tool.

One of the participants was M., a 34 year old Afghan man who had worked as an English translator, and who had been imprisoned and tortured by the Taliban. In one of his GIM sessions he processed his experience of fleeing Afghanistan. He remembered being in a hurry with people persecuting him, and having to cross a river that was very cold and had a strong undercurrent. There was only one rubber boat for him and ten other people, children included, whom were all trying to flee. $\mathrm{M}$. and another man decided to swim and push the boat, but is was so cold and difficult that M. almost passed out and had to be pulled up from the water by people on the other side. Listening to Arvo Pärt's "Spiegel im Spiegel" [15] he reexperienced the shock of going into the cold water. When Einaudi's piece, "I Giorni" [16], was played, the music changed M's imagery: two birds came and took all the people up into the air and flew them far away to a city where the birds then sat the people down on the ground, and everybody celebrated. After this experience $M$. sensed himself in a new way, and stated, "I am alive"! M. started to listen to music every day at home and it helped him to regulate his mood. In the final interview after the conclusion of therapy M. reported: "I can just feel it in my body, that [the] Taliban is not able to catch me again to $[s i c]$ the cave, and I think it is something that happened because of the music and the cooperation with my doctor [music therapist]."

Beck reports that the analyses are on-going, and all the results of this study will hopefully be published in 2016. It is certain that, with the on-going influx of refugees all over Europe and the rest of the world, there is a great need for increased research into effective trauma treatments that build 
resilience and help these traumatised populations thrive in their new countries of residence.

It is fitting that The Association for Music and Imagery will meet in Greece in September 2016 for its biennial European conference. In Greece, at the time of this writing, an average of 1000 refugees are arriving every day [17], and as previously cited, $35 \%$ of those refugees are at risk for PTSD. Perhaps Beck and her fellow researchers will be able to present the final results of their important research at this conference, and the GIM community can continue to move forward as significant contributors to global treatment of trauma.

In summary, these highlights from the Association of Music and Imagery conference are evidence that facilitators of the Bonny Method of GIM are contributing to the development of effective trauma treatments--exploring how music and imagery methods enhance current protocols and providing new ways of addressing symptoms.

\section{References}

1. CDC Violence Prevention page. Centers for Disease Control and Prevention Web site. Available at: [LINK]. Accessed October 1, 2015

2. Bonny, H.L. Music and consciousness: The evolution of guided imagery and music (L. Summer, Ed.). Gilsum, NH: Barcelona Publishers; 2002.

3. Summer, L. Addressing diversity through the music \& imagery and GIM continuum of practice. Keynote presented at: $23^{\text {rd }}$ International Conference of the Association for Music \& Imagery; July 16, 2015; Elizabeth, NJ.

4. Montgomery, E. \& Scott-Moncrieff, S. Trauma-Informed Guided Imagery and Music: A Phase-Oriented Approach. Paper presented at: $23^{\mathrm{rd}}$ International Conference of the Association for Music \& Imagery; July 16, 2015; Elizabeth, NJ.

5. Herman, J. L. Trauma and recovery. New York: BasicBooks; 1997.

6. Schwartz, R.C. Internal family systems therapy. New York, NY, US: Guilford Press; 1995.

7. Walter, D. H. GIM and its Adaption in the Treatment of CombatRelated PTSD with Veterans. Paper presented at: $23^{\text {rd }}$ International Conference of the Association for Music \& Imagery; July 18, 2015; Elizabeth, NJ.
8. Koelsch, S. \& Siebel, W.A. Towards a neural basis of music perception. Trends in cognitive sciences. 2005; 9(12): 578-584

9. Beck, B. D. GIM with Refugees Diagnosed with PTSD: A Qualitative Research Project. Paper presented at: $23^{\text {rd }}$ International Conference of the Association for Music \& Imagery; July 18, 2015; Elizabeth, NJ.

10. Masmas TN, Møller E, Buhmannr C, et al. Asylum seekers in Denmark. Torture. 2008; 18(2), 77-86.

11. Van der Kolk, B. A., van der Hart, O., \& Marmar, C. R. Dissociation and information processing in posttraumatic stress disorder. In: B. A. van, A. C. McFarlane, \& L. Weisaeth, eds. Traumatic stress: The Effects of Overwhelming Experience On Mind, Body, and Society New York, NY, US: Guilford Press; 1996: 303-327.

12. See Centre for Documentation and Research in Music Therapy website. Available at [LINK]. Accessed October 1, 2015.

13. Jespersen, K. V., \& Vuust, P. The effect of relaxation music listening on sleep quality in traumatized refugees: A pilot study. Journal of Music Therapy. 2012; 49(2): 205-229.

14. Alanne, S. Music Psychotherapy with Refugee Survivors of Torture: Interpretations of Three Clinical Case Studies. Sibelius Academy; 2010.

15. Pärt, (A). Spiegel im spiegel. Recorded by A. Malter, D. Schwalke, S. Bezrodny, \& V. Spivakov. On Alina [CD]. ECM Records; 1999: track 1

16. Einaudi, L. I giorni. On I giorni [CD]. Italy: BMG; 2001 : track 6

17. UNHRC News and Views page. The UN Refugee Agency Web site. Available at: [LINK]. Accessed October 1, 2015

\section{Biographical Statements}

Suzannah Scott-Moncrieff MA, MT-BC, LCAT, FAMI. Music therapist in private practice in New York City, USA. Faculty - New York University. Faculty - Institute for Music and Consciousness. President - Association for Music and Imagery

Bolette Daniels Beck Phd, FAMI, music therapist. Assistant professor at Institute for Communication and Psychology, Aalborg University, Denmark.

Erin Montgomery MEd, MTA, FAMI, RCT-C. Registered counseling therapist and accredited music therapist in private practice and with the Nova Scotia Health Authority, Halifax, Canada. Institute for Music and Consciousness - Faculty. Ethics Chair - Association for Music and Imagery 